\title{
Possibility of improvement of potentiodynamic method for monitoring corrosion rate of steel reinforcement in concrete
}

\author{
V Ž IVICA \\ Institute of Construction and Architecture of Slovak Academy of Sciences, Bratislava, Slovak Republic
}

MS received 20 September 2000

\begin{abstract}
Quantitative data on corroding steel reinforcement in reinforced concrete structures are undoubtedly very useful for evaluation of their service life and timely repairs. The method of electrode potential measurement is a convenient and simple test for this purpose, but it provides no quantitative data on corrosion rate and only information regarding active or passive state of steel reinforcement can be obtained. We show here the possibility of obtaining quantitative data on degree of corrosion of steel reinforcement by a potentiodynamic method. The developed method is based on experimentally estimated mathematical relation between the results of potentiodynamic method and degree of corrosion of steel reinforcement. It is possible to calculate the degree of corrosion of steel reinforcement using this mathematical relation and the measured values of current density by the potentiodynamic method.
\end{abstract}

Keywords. Steel reinforcement; corrosion rate; potentiodynamic method; electrical resistance method.

\section{Introduction}

Corrosion monitoring of the state of steel reinforcement in concrete is undoubtedly very useful. It can provide very important information relating to evaluation of service life of reinforced concrete structures. The conditions and processes that occur on steel reinforcement in concrete are electrochemical in nature. This fact makes possible the use of physicochemical methods like the method of electrode potential (Andrade and Gonzales 1978; Alekseev et al 1985; Andrade et al 1995) for monitoring the state of the steel reinforcement. However, these methods can only give information about the electrochemical state of the reinforcement, if it is passive or active. This represents a significant drawback of these methods. The method of linear polarization which is able to measure the corrosion rate is one exception (Stern and Geary 1957; Stern and Weisert 1959; Pequin and Chevalier 1971; Page and Havdahl 1985; Broomfield 1997). But even this method has several limitations:

(i) Choice of values of the constant $B$ in the Stern-Gear equation

$$
I_{\text {corr }}=\frac{B}{R_{\mathrm{p}}},
$$

where $I_{\text {corr }}$ is corrosion current and $R_{\mathrm{p}}$ the polarization resistance. The value of the constant $B$ is dependent upon the magnitude of kinetic coefficients of the anodic and cathodic reactions of the corrosion. It may vary from 26 to $52 \mathrm{mV}$. The deciding condition is if the steel is passive or active (Broomfield 1997). This condition makes the choice of the value of the constant $B$ very problematic, because the state of the steel may change. How to realize this is a problem.

(ii) The method detects the instantaneous corrosion rate.

(iii) The results of the method may have errors of 10 to 100, especially at low corrosion rate (Broomfield 1997).

(iv) When corrosion is concentrated on the top of the steel bars or, if the steel bars are close together or deep within the concrete the device may only send current to the top steel. Both of these errors mean that the best accuracy that can be expected from a linear polarization device is a factor of two to four (Broomfield 1997).

A dominant consequence of reinforcement corrosion is decrease in cross-section of the steel bars. This fact is used in the method of electrical resistance (MER). The method is based on the subsequent increase in electrical resistance of the corroding reinforcement, which is measured electrically. Several techniques of MER were developed and used (Freedman et al 1958; Schippa 1967). An improved MER technique is MER based on so-called corrosion sensor. The sensor is a properly modified specimen of reinforcement. The corrosion sensor is embedded in cement composite test specimens or the reinforced concrete structure and enables measurement of corrosion rate with sufficient sensitivity. It is important that various disturbing effects like ambient temperature changes, electrical tensions and others are excluded. Corrosion is indicated by increase in electrical resistance. Moreover, by means of the contingent equations and results of the MER, it is possible to calculate some characteristics of the corroding reinforcement, like decrease 
of section, depth of corroded layer and loss of steel material, and to estimate the corrosion rate. More detailed information about the MER is given elsewhere ( $\mathrm{Z}$ ivica 1997).

Comparison of the two methods shows that MER seems to be better than the method of linear polarization. One exception is limitation (ii), which is valid even for MER.

While evaluating the two methods the fact that the high heterogeneity of chloride-induced corrosion should be taken into consideration. This requirement is documented by the found values of variation coefficient of the MER results under the chloride-induced corrosion (Z $\mathrm{Z}$ ivica 1991).

It has been found that the values of variation coefficient may vary in a broad range, moreover depending on time of the exposure of the concrete. After 15 days of exposure it was $58 \%$, and after 170 days only $10 \%$. This shows high dispersion of the MER results especially in the initial stage of corrosion. For comparison under the same conditions, the results of stationary electrode potential method show a value of variation coefficient of around $8 \%$. The high dispersion of MER results observed is of pitting corrosion, which is a well known phenomenon of chlo-

Table 1. Composition and properties of cement CEM I $42 \cdot 5$.

\begin{tabular}{|c|c|c|c|}
\hline \multicolumn{2}{|c|}{ Chemical composition (\%) } & \multicolumn{2}{|c|}{$\begin{array}{l}\text { Mineralogical composition } \\
\text { (according to Bogue) }(\%)\end{array}$} \\
\hline Loss ignition & 1.77 & $\mathrm{C}_{3} \mathrm{~S}$ & $48 \cdot 9$ \\
\hline Insoluble residue & $1 \cdot 80$ & $\mathrm{C}_{2} \mathrm{~S}$ & $18 \cdot 4$ \\
\hline $\mathrm{SiO}_{2}$ & $19 \cdot 28$ & $\mathrm{C}_{3} \mathrm{~A}$ & $12 \cdot 0$ \\
\hline $\mathrm{CaO}$ & $61 \cdot 12$ & $\mathrm{C}_{4} \mathrm{AF}$ & $11 \cdot 3$ \\
\hline $\mathrm{Al}_{2} \mathrm{O}_{3}$ & $6 \cdot 91$ & $\mathrm{CaSO}_{4}$ & $4 \cdot 0$ \\
\hline $\begin{array}{l}\mathrm{Fe}_{2} \mathrm{O}_{3} \\
\mathrm{MgO}\end{array}$ & $\begin{array}{l}3.72 \\
1.69\end{array}$ & \multicolumn{2}{|c|}{ Physical properties } \\
\hline $\mathrm{SO}_{3}$ & 2.37 & Spec. surface area & $412 \mathrm{~m}^{2} \cdot \mathrm{kg}^{-1}$ \\
\hline $\mathrm{Na}_{2} \mathrm{O}$ & $0 \cdot 31$ & Spec. weight & $3124 \mathrm{~kg} \cdot \mathrm{m}^{-3}$ \\
\hline $\mathrm{K}_{2} \mathrm{O}$ & $0 \cdot 70$ & Norm. consistency & $35 \%$ \\
\hline $\mathrm{CaO}$ free & $0 \cdot 40$ & $\begin{array}{l}\text { Initial setting } \\
\text { Setting time }\end{array}$ & $\begin{array}{l}4 \text { h } 30 \mathrm{~min} \\
6 \mathrm{~h} 40 \mathrm{~min}\end{array}$ \\
\hline
\end{tabular}

ride-induced corrosion. Its development is heterogeneous, especially in the initial stage. With increased exposure the heterogeneity decreases as a result of the gathering of individual pitting points on the surface of the corroding steel. This undoubtedly affects the accuracy of measurement. Better accuracy of measurement may be expected in measurement of uniform corrosion (e.g. carbonation), where the effect of formation of pitting points is excluded and instead, uniform attack of the steel occurs.

The purpose of the present study was improvement of the potentiodynamic method (PDM) for the measurement of corrosion rate.

The improvement of PDM was based on the following: (i) to find the relationship between the proper PDM characteristic of the corroding reinforcement and the increase of corrosion sensor, $\Delta R$ measured by MER under the same conditions and (ii) to obtain a mathematical expression of the found relationship, giving the possibility of calculating $\Delta R$ using the results of PDM, and comparing the calculated $\Delta R$ values with those measured by MER.

\section{Experimental}

(i) Experimental study of steel reinforcement corrosion induced by chlorides by means of MER and PDM under defined and controlled conditions, and by means of visual inspection of the state of the steel reinforcement.

(ii) Finding the relation between MER and PDM results and then obtaining a mathematical expression of this relationship.

(iii) Comparison of measured and calculated values.

For the study, mortar test prisms of $40 \mathrm{~mm} \times 40 \mathrm{~mm}$ $\times 160 \mathrm{~mm}$ with embedded steel specimens were prepared. The composition of mortar mixtures were as follows: cement : silica sand :: $1: 3$, w/c 0.6 with $1.0,1.25,1.5$, $2 \cdot 0,3 \cdot 0$, and $4 \cdot 0 \%$ doses of calcium chloride added. Percentage values of doses are expressed from the weight of cement portion in the mixes. The prepared mortar test

Table 2. Results of the study on state of embedded steel specimens in mortars after 100 curing cycles.

\begin{tabular}{|c|c|c|c|c|c|}
\hline \multirow[b]{3}{*}{$\begin{array}{l}\text { Dose of } \\
\text { calcium } \\
\text { chloride } \\
(\%)\end{array}$} & \multirow{3}{*}{$\begin{array}{l}\text { Visual } \\
\text { inspection } \\
\text { Extent of } \\
\text { corrosion } \\
(\%)\end{array}$} & \multirow{3}{*}{$\begin{array}{c}\text { Electrical resistance } \\
\text { method } \\
\text { Increase of } \\
\text { electrical resistance } \\
(\mu \Omega)\end{array}$} & \multicolumn{3}{|c|}{$\begin{array}{c}\text { Potentiodynamic method } \\
\text { Polarization rate }\left(\mathrm{mV} \cdot \mathrm{min}^{-1}\right)\end{array}$} \\
\hline & & & 30 & 60 & 150 \\
\hline & & & $\begin{array}{l}\text { Current } \\
\text { density } \\
\left(\mathrm{A} \cdot \mathrm{m}^{-2}\right)\end{array}$ & $\begin{array}{l}\text { Current } \\
\text { density } \\
\left(\mathrm{A} \cdot \mathrm{m}^{-2}\right)\end{array}$ & $\begin{array}{l}\text { Current } \\
\text { density } \\
\left(\mathrm{A} \cdot \mathrm{m}^{-2}\right)\end{array}$ \\
\hline $1 \cdot 00$ & 30 & $28 \cdot 9$ & 0.420 & $0 \cdot 470$ & $0 \cdot 280$ \\
\hline $1 \cdot 25$ & 45 & $51 \cdot 1$ & 1.400 & $0 \cdot 880$ & $0 \cdot 690$ \\
\hline $1 \cdot 50$ & 50 & $62 \cdot 2$ & 4.050 & 1.450 & $0 \cdot 800$ \\
\hline $2 \cdot 00$ & 80 & $80 \cdot 0$ & $5 \cdot 900$ & $2 \cdot 900$ & 1.400 \\
\hline $3 \cdot 00$ & 90 & $95 \cdot 6$ & $7 \cdot 650$ & $8 \cdot 200$ & 1.600 \\
\hline $4 \cdot 00$ & 100 & $111 \cdot 1$ & $15 \cdot 000$ & $10 \cdot 050$ & $3 \cdot 400$ \\
\hline
\end{tabular}


specimens in moulds were cured for $24 \mathrm{~h}$ at ca $90 \%$ relative humidity and temperature of $20^{\circ} \mathrm{C}$. After demoulding, the test specimens were cured under regularly repeated cycles. One cycle represented curing at relative humidity of $75 \%$ and $20^{\circ} \mathrm{C}$ for $16 \mathrm{~h}$, and at $40^{\circ} \mathrm{C}$ for $8 \mathrm{~h}$. Temperature $40^{\circ} \mathrm{C}$ was chosen on the basis of our preceding research (Zivica et al 1997).

Test methods used: For the potentiodynamic measurement standard STN 731341 equipment and process were used. MER was used for the measurement of changes of electrical resistance of steel.

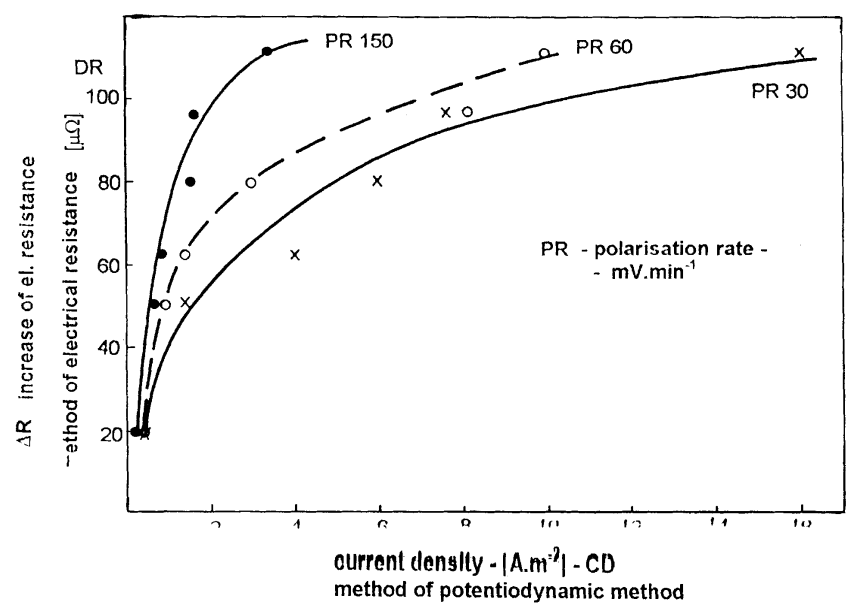

Figure 1. Relationship between values of current density and increase of electrical resistance of steel.

Table 3. Values of experimental coefficient of (2).

\begin{tabular}{lcc}
\hline & \multicolumn{2}{c}{$\begin{array}{c}\text { Values of experimental } \\
\text { coefficients }\end{array}$} \\
\cline { 2 - 3 } $\begin{array}{l}\text { Polarization rate } \\
\left(\mathrm{mV} \cdot \mathrm{min}^{-1}\right)\end{array}$ & $a$ & $b$ \\
\hline 30 & 0.0223 & 0.0078 \\
60 & 0.0125 & 0.0082 \\
150 & 0.0075 & 0.0067 \\
\hline
\end{tabular}

After 100 curing cycles, and the destruction of mortar test specimens by visual control, the extent of corrosion of steel test specimens was visually controlled. The extent of corroded area of total steel specimen area was expressed in per cent.

For the preparation of mortars, Portland cement CEM I 42.5 according to standard STN P ENV 197-1 (table 1), and silica sand according to standard STN 721208 were used. For the preparation of corrosion sensors construction steel according to standard STN 410425 was used. Calcium chloride used was chemically pure.

\section{Results and discussion}

A summary of the results of visual inspection, as well as MER and PDM results are given in table 2. It is seen that with the increase of calcium chloride doses in the mortar the values of electrical resistance were also increased indicating the increase of corrosion degree of steel. This fact was also visually confirmed. Analysis of the PDM results has shown that of the parameters enabled by this method like stationary potential, passivation potential, break-down potential, and current density, the last parameter showed a good relationship with the mentioned increase of electrical resistance of steel. It is seen that the values of current density increased with the progress of corrosion. Therefore, the dependence of current density on the increase of electrical resistance is shown in figure 1. It is evident that curves differed significantly depending on the polarization rate used at PDM. The increase of polarization rate used caused the decrease of the measured current density. The result was the shortening of the curves and their shift to the higher values of corresponding values of changes of electrical resistance of steel.

For the curves presented in figure 1, following function is relevant

$$
\Delta R_{\mathrm{c}}=\frac{\mathrm{CD}}{a+b \cdot \mathrm{CD}},
$$

Table 4. Measured and calculated values of changes of electrical resistance of embedded steel specimens.

\begin{tabular}{|c|c|c|c|c|c|c|}
\hline \multirow[b]{2}{*}{$\begin{array}{l}\Delta R \\
\text { measured } \\
(\mu \Omega)\end{array}$} & \multicolumn{6}{|c|}{$\begin{array}{l}\qquad \Delta R_{\mathrm{c}} \text { calculated }(2) \\
\text { Polarization rate }\left(\mathrm{mV} \cdot \mathrm{min}^{-1}\right)\end{array}$} \\
\hline & 30 & $\begin{array}{c}\text { Deviation of } \\
\Delta R_{\mathrm{c}} \text { opposite } \\
\Delta R(\%)\end{array}$ & 60 & $\begin{array}{c}\text { Deviation of } \\
\Delta R_{\mathrm{c}} \text { opposite } \\
\Delta R(\%)\end{array}$ & 150 & $\begin{array}{c}\text { Deviation of } \\
\Delta R_{\mathrm{c}} \text { opposite } \\
\Delta R(\%)\end{array}$ \\
\hline $28 \cdot 9$ & $16 \cdot 4$ & $-43 \cdot 3$ & $28 \cdot 3$ & $-2 \cdot 1$ & 29.9 & $+3 \cdot 5$ \\
\hline $62 \cdot 2$ & 74.6 & +19.9 & 58.9 & $-5 \cdot 3$ & $62 \cdot 2$ & 0 \\
\hline $80 \cdot 0$ & $86 \cdot 4$ & +8.0 & $79 \cdot 5$ & -0.6 & $82 \cdot 9$ & $+3 \cdot 6$ \\
\hline $95 \cdot 6$ & 93.0 & +2.7 & 102.6 & $+7 \cdot 3$ & 87.9 & $-8 \cdot 1$ \\
\hline $111 \cdot 1$ & $107 \cdot 4$ & $-3 \cdot 3$ & $108 \cdot 1$ & $-2 \cdot 7$ & $103 \cdot 7$ & $-6 \cdot 7$ \\
\hline
\end{tabular}




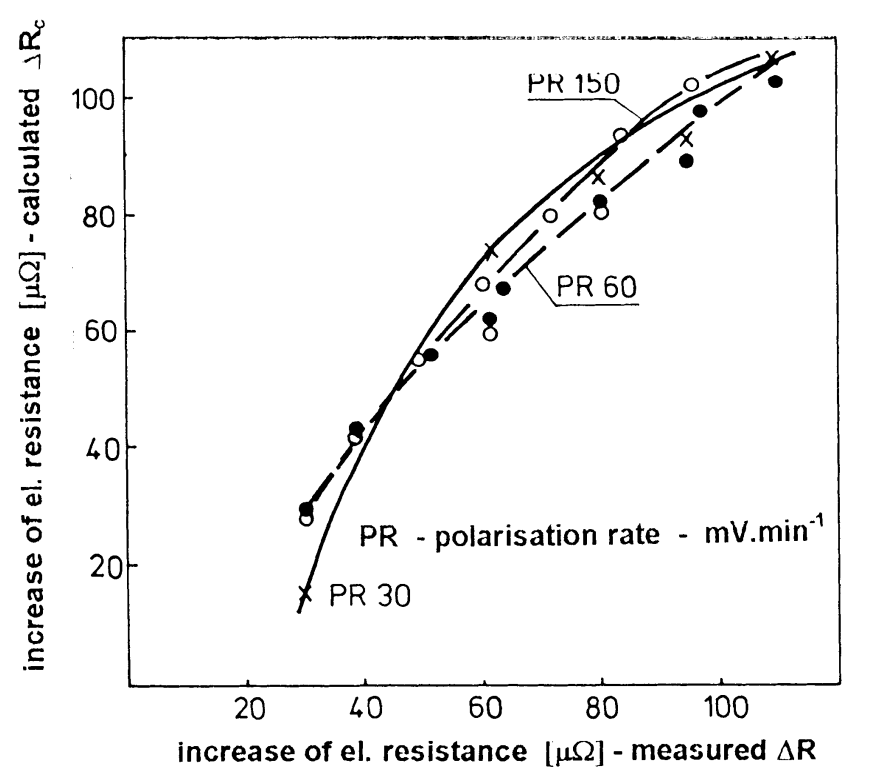

Figure 2. Relationship between values of increase of electrical resistance measured and calculated by means of (2).

where $\Delta R_{\mathrm{c}}$ is calculated value of change of electrical resistance of steel in $\mu \Omega, C D$ the value of current density in $\mathrm{A} \cdot \mathrm{m}^{-2}, a$ and $b$ are experimental coefficients.

After numbering, the values of the experimental coefficients given in table 3 were found. Then, by means of (2) it is possible to calculate the values of increase of electrical resistance of steel, $\Delta R_{\mathrm{c}}$, using measured current density values for the given polarization rate. The calculated values of $\Delta R_{\mathrm{c}}$ are given in table 4 . It is seen that when anomaly values of deviation -43.3 and $+19.9 \%$ are omitted, the calculated and measured $\Delta R$ values show very satisfied correspondence. This is shown in figure 2.

Using the values of $\Delta R_{\mathrm{c}}$ it is possible to calculate the reduction of section and material loss of the corroding reinforcement by means of the relationship of MER (Źivica 1995, 1997).

\section{Conclusions}

We show here the possibility to estimate some quantitative data on the corroding steel reinforcement by means of potentiodynamic method and of a calculation approach. This is based on the experimentally found mathematical relationship between potentiodynamically measured current density, and corrosion degree of steel reinforcement measured by means of electrical resistance.

\section{Acknowledgements}

The author is thankful to the Slovak grant agency, VEGA for financial support (grant 2/7033/21).

\section{References}

Alekseev S A, Ratinov V B, Rozental A K and Kashurnikov A M 1985 Inhibitors of corrosion of steel in reinforced concrete structures (Moskva: Stroizdat) (in Russian)

Andrade G and Gonzales J A 1978 Werkst. Korros. 29515

Andrade C, Alonso C, Feliu S and Gonzales J A 1995 Techniques to assess the corrosion activity of steel reinforced concrete structures (Philadelphia, PA: ASTM STP)

Broomfield J P 1997 Corrosion of steel in concrete (London: S\&FN Spoon)

Freedman A J, Trockinski E S and Drawnies H 1958 Corr. Mater. Assoc. Corr. Engg. 175t

Page C L and Havdahl J 1985 RILEM Mater. \& Struct. 41

Pequin P and Chevalier J L 1971 Corrosion 11188

Schippa G 1967 Proc. RILEM colloq. admixtures for mortars and concretes, Brussels, p. 127

Stern M and Geary A L 1957 J. Electrochem. Soc. 10456

Stern M and Weisert E D 1959 Proc. Am. Soc. Test. \& Mater. 591280

$\mathrm{Z}_{\text {ivica V }} 1991$ Corrosion of cement composites and their protective measures, D.Sc. Thesis, Institute of Construction and

Architecture of SAS, Bratislava

Z ivica V 1995 Bull. Mater. Sci. 18115

Zivica V 1997 Mater. \& Struct. 26328

Z Zivica V, Kračji L', Bágel'L' and Vargová M 1997 Construct. \& Building Mater. 1199 